\title{
THE MOTIVATION FOR ENGINEERING CHANGE IN THE INDUSTRIAL COMPANY
}

\author{
Augustinas MACEIKA (D*, Eligijus TOLOČKA (D) \\ Department of Mechanics and Materials Engineering, Faculty of Mechanics, \\ Vilnius Gediminas Technical University, J. Basanavičiaus street 28, LT-03224 Vilnius, Lithuania
}

Received 25 June 2020; accepted 13 December 2020

\begin{abstract}
The authors of this article established the goal to investigate parameters related to the staff motivation_for engineering change in the industrial company as case study and to predict the ways of improving the performance of the company. Employees of the company can be more motivated to generate innovative ideas and to implement them. That can be related to the better engineering change situation. For this reason, in this work, we have explored the environment and opportunities to improve the engineering performance of the company in the context of engineering change. The authors of the paper have conducted several studies, collected and analysed important information. Methods used - review of scientific literature and other sources of information, case study, structural systematic analysis, and sociological survey of industrial company personnel based on hypothesis. The object of the research was motives for engineering change in the industrial company. Motivated organizational behaviour actions, that focus on creation and realization of innovative ideas for engineering change, can be based on creation of an innovation-friendly environment. As our research has shown, it is important to consider parameters related to the staff motivation, such as, satisfaction with the company's declared policy, satisfaction with the management's behaviour in encouraging employees, freedom of employees to communicate and take creative initiative.
\end{abstract}

Keywords: motivation, engineering change, industrial company, organizational behaviour, innovation.

JEL Classification: D22, D24, J28, O14, O31, O33.

\section{Introduction}

Continuous product improvement in order to meet the needs of consumers better and the desire to make business processes as efficient as possible creates preconditions for more active participation in carrying out engineering changes. Growing of the market competitive pressure and exceptional consumer needs are contributing to the acceleration of business renewal. For industrial companies, this renewal often means engineering change through innovation. The activities of modern companies are associated with the employees' involvement in the process of improvements in the field of products and production. Suppliers and consumers are also often involved in to decisions for product improvement. In order to get better results in the course of engineering changes, it is necessary to apply motivational measures to encourage both the company's employees and business partners.

The goal of the research was to investigate parameters related to the staff motivation for engineering change in the industrial company based on case study and to predict the ways of improving the performance of the company.

The object of the research was motives for engineering change in the industrial company.

Identification of the problem. Industrial companies face constant challenges in product and processes improvement. In some of them, there is a lack of dissemination of information on quality policy and motivation to more complex engineering change in revolutionary changing environment, when the behaviour of personnel and business partners changing too. Also, behaviour of employees, that particitating in the engineering change, is required to be more detail researched and planned measures to improve it can be analysed. Employees of the company can be more motivated to create and implement innovative ideas if there can be more freedom and available resources for initiatives. That can be related to the better engineering change situation. The research problem is defined as follows: there is a causal between the staff motives for engineering change, the engineering situation and the

${ }^{\star}$ Corresponding author. E-mail: augustinas.maceika@vilniustech.lt

Copyright $\odot 2021$ The Author(s). Published by Vilnius Gediminas Technical University

This is an Open Access article distributed under the terms of the Creative Commons Attribution License (http://creativecommons.org/licenses/by/4.0/), which permits unrestricted use, distribution, and reproduction in any medium, provided the original author and source are credited. 
frequency of engineering changes in the product and the manufacturing process.

\section{Overview of the reasons and the process of engineering change}

Lots of authors point out that engineering change is extremely important for the successful operation of the industrial company.

According to Do (2018), engineering changes are inevitable processes in manufacturing companies, and their efficient management is a critical factor in maintaining the competitiveness of a company.

According to Huang et al. (2003), engineering changes are changes and/or modifications in the dimensions, packaging, shape, function, material and similar features of products or their components after the product concerned has been released.

Chen et al. (2017) argues that engineering change is an important business activity and driving force of product innovation related to the different impact domains in different change environments.

According to Ullah et al. (2016), the objective of engineering change management is to minimize the occurrence of changes and if changes occur then handle these changes in a proper way to reduce the loss in terms of cost, time and quality and to manage engineering changes effectively it is necessary that it must be set as an organizational goal and its accomplishment must be planned prudently.

Some of the factors that regularly trigger engineering changes are (VDA, 2010):

1. Legislative changes;

2. Changes in the market conditions or competitive position;

3. Internal deficiencies in development, planning, or production;

4. Quality or safety issues;

5. Exploiting of additional optimization potential.

Engineering changes can be caused by a variety of reasons. On the different stages of the product development process this can be (Pikosz \& Malmqvist, 1998):

1. Changes in the customer specification;

2. Faults in the interpretation of customer demands into technical requirements;

3. Difficulties in parts fabrication or assembly;

4. Weaknesses in the product identified during prototype testing;

5. Quality problems with some subsystem or component;

6. Development for future product revisions.

Schuh et al. (2018) presented engineering change management complexity enablers categories: resource allocation, qualifications, team composition, organizational interfaces, individual motivation, directives and control, accountability, stuctural formalization, contextual support, document availability, data structure ubiquity, data structure utility, experimental knowledge storage, process flexibility, process support for experiential learning, organic processes, breadth of approval requirements, serial vs. parallel process, diversity of simulteneous tasks, communication intensity, comunication istitutionalization, communication formalization. Schuh et al. (2018) also presented engineering change management complexity drivers: complexity of stakeholder and goal, quality requirements, vertical integration, culture, product technical complexity, product innovation and novelty, product variety, process scope, company features.

The process of engineering change consists of stages (VDA, 2010):

1. Identification of potential for change;

2. Development of alternative solutions;

3. Specification of and decision on change;

4. Engineering implementation of change;

5. Manufacturing implementation of change.

Siddharth and Sarkar (2017) argues that every change that starts with design propagates through materials, processes, machines, labour, and operating time, terminates with cost that remains very crucial part in decision making.

According to Schuh et al. (2017), during the early stage, a product change entails far less implications on other departments, for manufacturing there is little relevant information at this stage as e.g. work instructions and process plans are only rudimentary, at the late stage, more departments need to be involved and additional quality insuring steps are needed: work flows for releasing an engineering change now also have to take into consideration tool making, standards that have to be met and the effort of documenting changes connected to these elements.

Many stakeholders can be involved in the process of complex engineering change. According to Shakirov et al. (2019), various stakeholders were identified and grouped into main representatives: Product Development dept., Manufacturing Engineering dept., System Management dept., Inspection \& Testing dept., Logistics dept., Manufacturing System Operating dept., Suppliers, Customer, Sales and Marketing dept.

Shaikh and O'Connor (2020) used a longitudinal multi-case comparison design to examine the corporate governance systems of industry-leading companies, and argued that incumbent firms struggle with radical innovation because opportunistic managers overinvest free cash flows into radical ideas, with limited commercial value and that the challenge lies less in the middle manager's desire to enrich themselves at the expense of the shareholders, on the contrary, it arises more from a failure to suitably select, invent and monitor the commercialization activities associated with technological innovation, the farther removed it is from the initial recognition of the opportunity.

According to Iakymenko et al. (2018), while the explicit knowledge on engineering changes is usually documented, although often in different IT systems across the company, tacit knowledge is not captured and therefore lost when an employee retires or changes work place, so 
there is a need to develop processes and tools for capturing and reusing knowledge generated by both engineers, planners and shop floor workers during the engineering change implementation process.

\section{Motivation of the industrial company employees and business environment for participation in engineering change}

Motivation of the industrial company employees and business environment for participation in engineering change is based on meeting the needs of stakeholders. Modern motivation is based on activities to deliver benefits to consumers, employees and partners of the organization and society at large, and to turn those parties into the results and success of the organization. It is equally important to know the expectations of motivated people, their understanding of justice, their worldview, and cognition.

Current engineering changes are associated with environmental motivation. The paper of J. González-Benito and O. González-Benito (2005) studies the relationship between the environmental motivations or beliefs prevailing in a company and the kind of environmental transformation the company is undertaking, and it was found that ethical motivations, which refer to the desire of decision makers to enhance the company's environmental performance, tend to favour the environmental transformations of the management and commercial system, although these transformations are not able to alter environmental performance if they are not accompanied by operational changes.

The empirical results of Singh et al. (2015) show that firms consider relational motivations as a significant driver influencing environmental responsiveness, indicating that firms are more likely to adopt comprehensiveness of firms' environmental management systems practices, for better compliance, prevention of environmental incidents and to portray the image of an environmentally responsive firm.

The motivated initiative of the company's employees to offer and implement engineering changes is stronger if it is their personal idea. Howard et al. (2016) research results support the hypothesis that autonomous forms of motivation are far more important in promoting positive workplace outcomes than more controlling forms.

A survey of Mitchell et al. (2020), across multiple industries, shows that extrinsic motivation can decrease employees' autonomy and competence needs satisfaction, but when extrinsic motivation is internalized (such as through perceived personal value) it can support needs satisfaction, intrinsic motivation, and behavioural intention.

Table 1. Relationship between parameters studied in this article and parameters studied by various authors (source: prepared by the authors based on Iakymenko et al. (2018), C.-G. Alexe \& C.-M. Alexe (2018), Rusu \& Avasilcai (2014), Ozkeser (2019), Eide et al. (2020))

\begin{tabular}{|c|c|c|c|c|c|}
\hline $\begin{array}{l}\text { The parameters investigated in current } \\
\text { article }\end{array}$ & $\begin{array}{l}\text { Iakymenko } \\
\text { et al. (2018) }\end{array}$ & $\begin{array}{l}\text { C.-G. Alexe and } \\
\text { C.-M. Alexe } \\
(2018)\end{array}$ & $\begin{array}{c}\text { Rusu and } \\
\text { Avasilcai } \\
(2014)\end{array}$ & $\begin{array}{l}\text { Ozkeser } \\
(2019)\end{array}$ & $\begin{array}{l}\text { Eide et al. } \\
\quad(2020)\end{array}$ \\
\hline Engineering situation & $\mathrm{X}$ & & & & \\
\hline Product improvement & $\mathrm{X}$ & & & & \\
\hline Logistics improvement & $\mathrm{X}$ & & & & \\
\hline Manufacturing process improvement & $\mathrm{X}$ & & & & \\
\hline Information activities improvement & $\mathrm{X}$ & & & & \\
\hline Satisfaction with the policy & & & $\mathrm{X}$ & & \\
\hline Appropriateness of management assistance & & $\mathrm{X}$ & $\mathrm{X}$ & & \\
\hline Tolerance of creative initiative & & $\mathrm{X}$ & $\mathrm{X}$ & & \\
\hline Tolerance of creative activity & & $\mathrm{X}$ & $\mathrm{X}$ & & \\
\hline Wage satisfaction & & $\mathrm{X}$ & $\mathrm{X}$ & $\mathrm{X}$ & \\
\hline Trust in professionals & & $\mathrm{X}$ & & & \\
\hline Freedom of communication & $\mathrm{X}$ & $\mathrm{X}$ & & & \\
\hline Role structuring & & & $\mathrm{X}$ & & \\
\hline Guidance by trust in allocation of roles & & $\mathrm{X}$ & & & \\
\hline Guidance by competency & & $\mathrm{X}$ & $\mathrm{X}$ & & \\
\hline Frequency of conflicts & & & $\mathrm{X}$ & & \\
\hline Freedom to improve production processes & & $\mathrm{X}$ & $\mathrm{X}$ & & \\
\hline Suitability of equipment & & & $\mathrm{X}$ & & \\
\hline $\begin{array}{l}\text { Direction and motivation of tasks in } \\
\text { production processes }\end{array}$ & & $\mathrm{X}$ & $\mathrm{X}$ & $\mathrm{X}$ & \\
\hline $\begin{array}{l}\text { Behaviour analysis of engineers and } \\
\text { managers }\end{array}$ & & $\mathrm{X}$ & & & $\mathrm{X}$ \\
\hline
\end{tabular}


According to Kuvaas et al. (2017), intrinsic motivation was associated with positive outcomes and that extrinsic motivation was negatively related or unrelated to positive outcomes.

The company's policy of motivating employees is important one. The results of Lau et al. (2018) indicate that organizational politics clearly has significant effects on budgetary participation, therefore, the key message from the results of this study is that there is a need for top management to not only account for and manage politics, but also to monitor and manage the actions of both the superiors and the subordinates in different ways in the management of organizational politics in the budgeting context.

The parameters investigated by this article authors and presented in the Table 1 are related to the parameters examined in the works of other authors, but in this article, we additionally discuss the situation of task formation, fear of various issues in communication with the supervisor, employee characteristics matching to work, and self-confidence. The scope of research by other authors also varies, for example, Rusu and Avasilcai (2014) also examined the parameters of financial conditions, job security, recognition, promotion, personal development, feelings about work colleagues, physical ambience, work conditions. Eide et al. (2020) further investigated in the context the sustainability strategy parameters of objective measures of profitability and income growth, leaders' perceptions of value creation, motivation for sustainability, and intellectual leadership.

In order to improve quality continuously, it must be taken into account that monetary remuneration does not always provide good motivation. According to Maslow (1943), physiological and safety needs which are primary and then secondary - love, esteem, and self-actualization, can be met, in addition, people are motivated by the desire to achieve or maintain the various conditions upon which these basic satisfactions rest and by certain more intellectual desires. Employees are motivated to do the job that is paid, safe and needs-driven.

The institutional support for development and technological capability is important too. According to Yu et al. (2020), during the China industry transformative periods, different business strategies including market strategies, technological strategies, and talent strategies are adopted under the interaction of local-central institutional environment and technological changes.

Members of the society needs to be aware that universal participation in quality improvement is a means of preventing fragmentation, backwardness and disasters due to poor quality in one of the areas, also to decrease the lack of resources or limiting them to necessary activities. If all members of society were involved in quality improvement, their abilities and actions would overlap, will ensure environmental motivation, sustainable development, and enable communities to flourish.

\section{Research methodology}

The research consisted from steps:

1. Formulation of the goal for research as case study;

2. The study of the motives for engineering change in the industrial company;

3. The analysis and evaluation of the obtained from the respondents' data by using an average value method, correlation regression analysis method;

4. Development of the process of engineering change by using a structural systematic analysis method;

5. Writing conclusions based on the results of the case study.

A large Lithuanian industrial company was selected for the case study. This company was actively engaged in innovative activities and engineering changes. The case study of one company was chosen because it was intended to investigate an authentic situation without distorting the assessment of possible factors, due to possible overlapping that occurs when examining the companies of different types and conditions.

Employees' attitudes and the needs to improve the quality of the product and manufacturing process creates a motivating field for engineering change.

The main hypotheses of the study were formulated as follows:

Hypothesis H1. The engineering situation in the company can be related to the frequency of engineering changes in the product and the manufacturing process;

Hypothesis H2. The frequency of engineering changes can be related to the satisfaction with the company's declared policy;

Hypothesis $\mathrm{H} 3$. The frequency of engineering changes can be related to the satisfaction with the management's behaviour in encouraging employees to address engineering changes related quality issues;

Hypothesis $\mathrm{H} 4$. The frequency of engineering changes can be related to the wage satisfaction;

Hypothesis H5. The frequency of engineering change can be related to the freedom of employees to communicate and take creative initiative.

\section{Research results}

As a practical case study of the economic-social motivation situation of engineering change, the industrial company was investigated. During the survey the 15 respondents of engineering and managerial staff was questioned.

The engineering situation was found to be good. Engineering situation was rated 4.1 out of 5 points (responses were rated on a scale of 1 to 5)). Product and manufacturing process improvement frequencies were respectively evaluated by 4.2 and 4.6 points. Frequencies of logistics and information activities improvement were respectively evaluated by 3.6 and 3.8 points.

Employees also rated the suitability of the equipment for production tasks on average by 4.1 points, but direction and motivation of tasks in production processes were 
less evaluated - on average by 3.9 points. The freedom to improve production processes was evaluated by 3.5 points. It is therefore concluded that, the company's engineering equipment and devices, technological manufacturing methods, which include organizational structure elements, can be constantly improved. Also, it is appropriate for the company to prepare for the modernization of technical production based on engineering changes and systematic engineering management.

The necessary engineering changes at the researched company would be made even more robust by the development of innovative solutions for the appropriate information, logistic, and engineering processes with application of the systematic engineering approach. Ultimately, however, the implementation of carefully prepared engineering changes would require the improvement of appropriate internal operating conditions and their management.

It was also found that only 33 per cent of the respondents indicated that the company had a policy for the participation of engineering and management personnel in creative activities, the majority (60 per cent of the respondents) did not know anything about it, the rest answered that there are no such kind of politics.

During evaluation of the engineers and managers behaviour situation in the studied company, the managers indicated that the behaviour analysis does not take place. Most engineers did not know anything about behaviour analysis and the processes associated with it, but 23.1 percent of them indicated that behaviour analysis was taking place, which contradicted to the opinion of the managers. In summary, there is a lack of behaviour assessment and misunderstanding among the employees of the researched company and there is no systematic approach to problem solving in this area. An informal approach prevails in the field of behaviour analysis, which can in part creates free conditions for creativity, but does not show an organized effort to improve the situation in this area.

It is appropriate to make innovative organizational and management changes in the organizational behaviour of the company. For example, research shows that the engineering tasks, formulated by managers (about 3.6 out of 5 points) prevailed over the engineers, who rated their influence on the tasks by 3.2 out of 5 (see Figure 1).

This is not a bad case, but given the need for new ideas and innovation, the contribution of engineers to the task must be increased.

An evaluation of the parameters related to the staff motivation in the industrial company is presented in the Figure 2.

It is appropriate to prepare changes in management activities to improve the engineering change process based on survey data. For example, the problem of structuring roles in the distribution of the tasks for the engineers was rated on average by approximately 3.6 out of 5 (see Figure 2).

These figures show that there is still place for improvement in organizational behaviour in engineering activities field. Based on the other examined results, it is a logical component of engineering change.

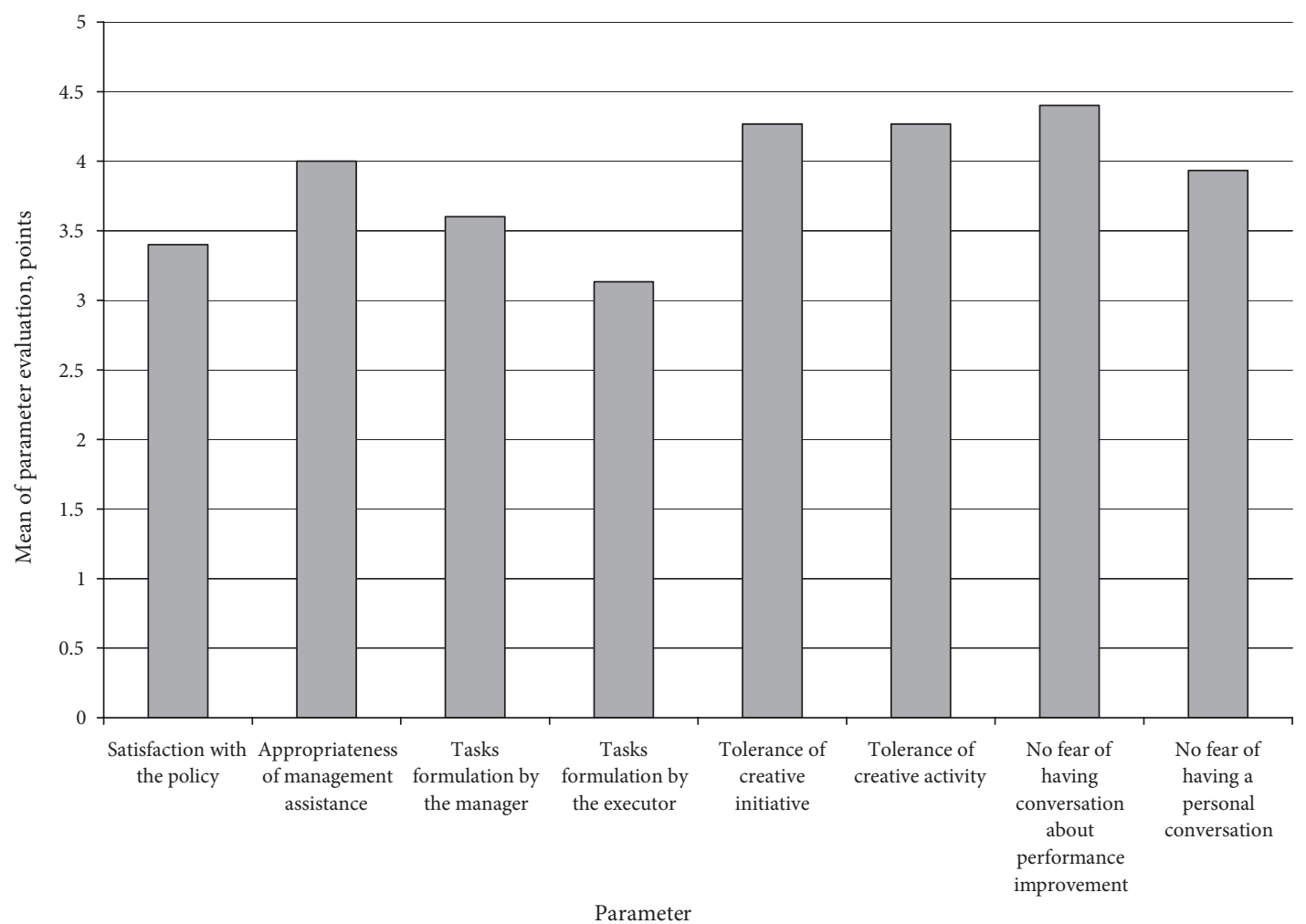

Figure 1. Evaluation of the employee-manager relationships in tasks performing (source: prepared by the authors) 


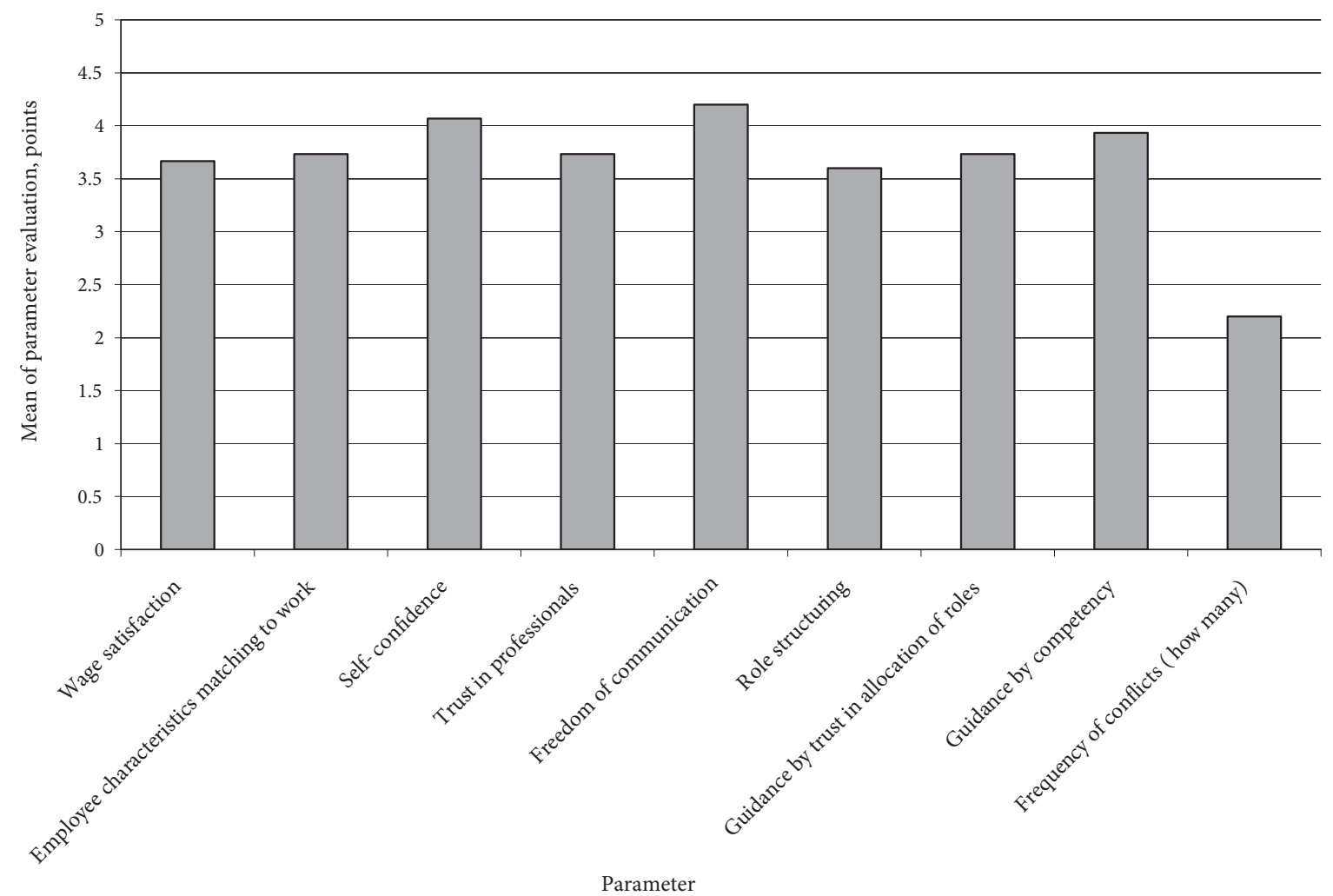

Figure 2. Evaluation of the parameters related to the staff motivation in the industrial company (source: prepared by the authors)

The mean values, standard deviation (SD), and correlation coefficient $(r)$ of the respondents' responses are presented in Table 2.

As can be seen from the Table 2, Hypothesis H1, that engineering situation can be related to the frequency of engineering changes in the product and the manufacturing process, proved because the correlation coefficients were found to be moderate positive.

Hypothesis H2, that the frequency of engineering changes can be related to the satisfaction with the company's declared policy, proved in the field of product improvement and not proved in the field of manufacturing process improvement. The product improvement parameter was strongly correlated with the satisfaction with the policy parameter $(r=0.785)$, which was not observed in the manufacturing process improvement and satisfaction with the policy correlation $(r=0.196)$. Also, the satisfaction with the policy parameter was most strongly correlated with the engineering situation parameter $(\mathrm{r}=0.785)$.

The frequency of conflicts parameter had negative $r$ values with respect to the studied parameters, where the correlation was moderate or weak.

Hypothesis $\mathrm{H} 3$, which aims to evaluate relationships between the frequency of engineering changes and satisfaction with the management's behaviour in encouraging employees to address engineering changes related quality issues, partially proved. The parameter of direction and motivation of tasks in production processes was most strongly correlated with the engineering situation $(\mathrm{r}=$ $0.491)$ and product improvement parameters $(r=0.483)$.
It was also found that the appropriateness of management assistance was most strongly correlated with employee characteristics matching to work $(r=0.635)$, freedom of communication $(r=0.764)$, and frequency of conflicts parameters $(\mathrm{r}=-0.655)$.

Hypothesis H4, under which the frequency of engineering changes can be related to the wage satisfaction not proved in the field of product improvement $(r=0.171)$ also in the field of manufacturing process improvement $(\mathrm{r}=0.183)$.

The wage satisfaction parameter was low than average correlated with the engineering situation $(r=0.301)$, satisfaction with the policy $(r=0.32)$, and appropriateness of management assistance $(r=0.411)$ parameters.

Studies showed that people were satisfied with their salary ( 3.7 points out of 5 possible on average).

Hypothesis H5, that the frequency of engineering change can be related to the freedom of employees to communicate, was mostly proved for product improvement, where the coefficient of correlation was $r=0.6$. The parameter of tolerance of creative initiative mostly correlated with the manufacturing process improvement $(\mathrm{r}=$ $0.578)$ and satisfaction with the policy $(r=0.48)$ parameters.

\section{Discussion}

In the surveyed company, satisfaction with the policy was strongly related to the engineering situation, product improvement, but most of respondents indicated that they 
were unaware of the policy for the participation of engineering and management personnel in creative activities. There is a misunderstanding which requires more detail research. Improvement and communication of the policy should have a strong impact on improvement of the engineering situation and motivation for necessary engineering change.

Appropriateness of management assistance was linked to the freedom of communication and employee characteristics matching to work, and this parameter had a closeto-average correlation with wage satisfaction. Properly managed company's engineering change implementation process can help to understand and improve organizational behaviour. Unfortunately, research in the company as well as practical experience showed that this is often the case with a lack of awareness, an obvious element that leads to fundamental misunderstandings and a disproportionate desire to maximize profits. As can be seen from our study, the evaluation of the situation of the engineers and managers behaviour in the researched company is practically non-existent, and there could be great potential to provide measures for better employee motivation and more efficient work. Myopia does not make it possible to encourage greater investment in the development of innovation. There has to be long-term strategic thinking. It is the responsibility of management to prove that sustainability is a long-term goal.
Accordingly, a structural systematic analysis method was used to detail and systematize the process of engineering change in order to carry out the respective researches and to realize the established regularities of engineering change.

The process of shaping engineering change from start to implementation of the project is shown in the Figure 3. This process is related to the motivation activities at each stage.

From this figure we can see that it is expedient to start the search for relevant engineering changes from the assessment of business environment and company's processes.

The process of engineering change involves a sequence of decisions, the adequacy and accuracy of which depend on the appropriate motivations of decision makers and the determination to pursue effective engineering changes that will help the company further business development, is presented in Figure 3. This update of the motivational system is possible with the results of the research presented earlier in this article, integrating them into the proposed process of engineering change.

Motivation for engineering change can arise from external or internal reasons or both. External reasons predominate when an industrial company faces threatening solutions from competitors when operating and

Table 2. Average estimation and correlation of engineering change related researched parameters (source: prepared by the authors)

\begin{tabular}{|c|c|c|c|c|c|c|c|c|c|c|c|c|c|c|}
\hline No. & Parameter & Mean & SD & 1 & 2 & 3 & 4 & 5 & 6 & 7 & 8 & 9 & 10 & 11 \\
\hline 1 & $\begin{array}{l}\text { Engineering } \\
\text { situation }\end{array}$ & 4.133 & 0.64 & 1 & & & & & & & & & & \\
\hline 2 & $\begin{array}{l}\text { Product improve- } \\
\text { ment (frequency } \\
\text { of changes) }\end{array}$ & 4.2 & 0.676 & 0.594 & 1 & & & & & & & & & \\
\hline 3 & $\begin{array}{l}\text { Manufacturing } \\
\text { process improve- } \\
\text { ment (frequency } \\
\text { of changes) }\end{array}$ & 4.6 & 0.633 & 0.494 & 0.535 & 1 & & & & & & & & \\
\hline 4 & $\begin{array}{l}\text { Satisfaction with } \\
\text { the policy }\end{array}$ & 3.4 & 1.140 & 0.785 & 0.785 & 0.196 & 1 & & & & & & & \\
\hline 5 & $\begin{array}{l}\text { Appropriateness } \\
\text { of management } \\
\text { assistance }\end{array}$ & 4 & 0.845 & 0.396 & 0.25 & 0.267 & 0.067 & 1 & & & & & & \\
\hline 6 & $\begin{array}{l}\text { Tolerance of } \\
\text { creative initiative }\end{array}$ & 4.267 & 0.704 & 0.074 & 0.33 & 0.578 & 0.48 & 0.24 & 1 & & & & & \\
\hline 7 & Wage satisfaction & 3.667 & 0.617 & 0.301 & 0.171 & 0.183 & 0.32 & 0.411 & 0.055 & 1 & & & & \\
\hline 8 & $\begin{array}{l}\text { Employee } \\
\text { characteristics } \\
\text { matching to work }\end{array}$ & 3.733 & 0.799 & 0.354 & 0.106 & 0.481 & 0.48 & 0.635 & 0.517 & 0.531 & 1 & & & \\
\hline 9 & $\begin{array}{l}\text { Freedom of } \\
\text { communication }\end{array}$ & 4.2 & 0.775 & 0.231 & 0.6 & 0.321 & 0.219 & 0.764 & 0.288 & 0.149 & 0.323 & 1 & & \\
\hline 10 & $\begin{array}{l}\text { Frequency of } \\
\text { conflicts (how } \\
\text { many) }\end{array}$ & 2.2 & 0.775 & -0.346 & -0.218 & -0.408 & -0.346 & -0.655 & -0.105 & -0.299 & -0.485 & -0.548 & 1 & \\
\hline 11 & $\begin{array}{l}\text { Direction and } \\
\text { motivation of } \\
\text { tasks in produc- } \\
\text { tion processes }\end{array}$ & 3.867 & 0.743 & 0.491 & 0.483 & 0.03 & 0.31 & 0.341 & 0.209 & 0.052 & 0.297 & 0.298 & 0.05 & 1 \\
\hline
\end{tabular}


researching new or changed market, or when customers themselves turn to the firm and express new preferences that require engineering change.

In the Figure 3, motivation for engineering change inspired by external factors may occur in those parts of the process that are marked with a dashed frame line, and motivation inspired by internal factors may occur in those places in the process that are marked with a bolded frame line. And positions in which both groups of factors operate are marked with a dashed bolded frame line.

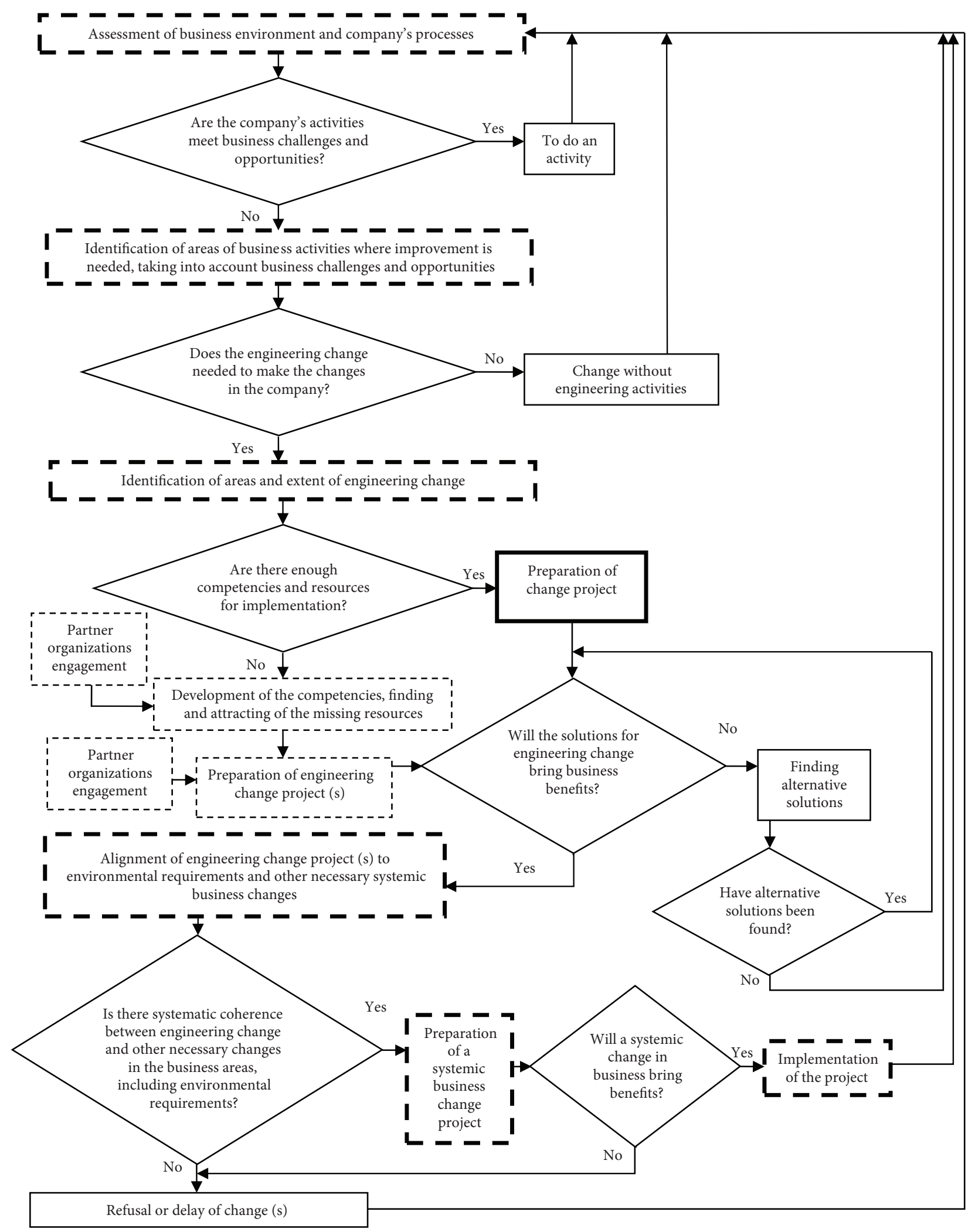

Figure 3. Suggested process of engineering change (source: prepared by the authors) 
The measured employee motivation parameters presented in Figure 2 reflect the internal motivation factors of the company's human resources that can inspire engineering change.

There is no doubt that engineers and managers, as professionals, are involved in engineering change, its implementation and practical application stages. However, in these phases there is an intrusion of already known operations specialists, which is related to the acquired knowledge of performing different technological operations and the use of practical working methods. The creative efforts and work of these employees in the field of engineering changes shapes and content changes that are related to the conditions of the existing and potential production situation. In this way, the preparation for the implementation of engineering changes takes place, if not completely economically, but already under control of the economic cost position.

Reasons and motives for decision making can be identified after analysis of business activities where improvement is needed, taking into account business challenges and opportunities. Also, the question about engineering change areas and extent of engineering change can be answered.

Another question is for evaluation of the competencies and resources for implementation. There must be enough motivation and possibilities for development of the competencies, finding and attracting of the missing resources.

Partners' organizations are often involved in the engineering change processes. Partners' motivation to put efforts for engineering change support can be crucial for the success.

Alignment of engineering change projects to environmental requirements and other necessary systemic business changes is related to the policy of the company, especially in the field of sustainability. This is important, because the results of research in the selected company show that the policy can have a strong impact on engineering situation and the frequency of product improvement.

If it is found that the solutions for engineering change will bring business benefits, the preparation of a systemic business change project can be started. Therefore, we should not only carry out an engineering-economic analysis of innovative ideas and innovations, but also analyse the planned engineering changes finding alternative solutions, if required.

The practical implementation of change in a company can begin by considering whether the benefits of engineering change are fully in line with the economic and social expectations of company executives and designers, and the layout of operational, tactical, and strategic phases at appropriate stages of production development.

It is also important to take into account the experience gained in this field before starting new engineering changes. Grieco et al. (2017) analysed opportunities to learn from previous projects using Self Organizing Map for Engineering Change Requests texts exploration by clustering.
In the field of engineering change, it is useful to apply tools that facilitate the evaluation of potential outcomes. Zheng et al. (2019) proposed a novel approach in this field that was based on modular analysis, robustness evaluation, and cost-sensitive learning, to support engineering change management in the smart product service systems.

\section{Conclusions and suggestions}

1. The case study of the selected industrial company revealed that the satisfaction with the policy is strongly related to the engineering situation and product improvement frequency by correlation $(\mathrm{r}=0.785)$, while it is less related to the improvement of the production process $(r=0.196)$. As the policy sets out general guidelines for activities, it brings clarity when operating in a changing environment, and is useful in motivating employees to respond adequately to challenges and opportunities. It is worth paying more attention to the company's policy development and its publicity to improve the performance of the company;

2. Satisfaction with the management's behaviour in encouraging employees to solve engineering changes related quality problems, can be linked to the better engineering and product improvement situation. In order to improve management assistance and organizational behaviour, it is important to identify barriers for creativity in innovation teams and use tools to reduce those barriers. Certain organizational behaviour can be created by the organization itself or copied from successful organizations, in some cases, organizational behaviour can be transferred through technology acquisition and staff training, 6 Sigma, theory of constraints systems, Lean production-related Kaizen, Kanban, just-in-time manufacturing, and similar methods;

3. Freedom of employees to communicate and take creative initiative can be significant stimulus for product and manufacturing process improvement. There is considerable potential for software acquisition and customization in product data and life cycle management, business management systems, computer aided design, computer aided manufacturing and computer aided engineering;

4. Wage satisfaction in the researched company was evaluated by 3.7 points in average and less than average correlated with the engineering situation $(r=0.301)$, satisfaction with the policy $(r=0.32)$, and appropriateness of management assistance $(r=0.411)$ parameters. Here, it is worth to take more attention to the needs and interests of those involved in engineering changes. Employees are motivated not only by the belief that effort will be rewarded, but also by the perception of the correct contributionreward relationship. Motivated organizational behaviour actions that focus on creation and realization of ideas providing an innovation-friendly environment are important for successful engineering change. It is also worth to pursue motivated action for sustainable development, so that engineering change projects will be adapted to environmental requirements and the long-term needs of society; 
5. Based on the case study and the analysis of environmental factors, a sophisticated process for introducing of engineering changes into companies' innovative activities is proposed. The process includes companies' internal motivation for the change, the impact of external factors, the involvement in the necessary cooperation with the partners, environmental assessment, and compliance with business objectives.

\section{Author contributions}

The contributions of both authors of the article were equal.

\section{Disclosure statement}

The authors of the article have no conflicts of interest.

\section{References}

Alexe, C.-G., \& Alexe, C.-M. (2018). Similarities and differentiations at the level of the industries in acquiring an organizational culture in innovation. In the 11th International Conference Interdisciplinarity in Engineering, INTER-ENG 2017, Tirgu-Mures, Romania, Procedia Manufacturing, 22, 317-324. https://doi.org/10.1016/j.promfg.2018.03.048

Chen, J., Zhang, S., Wang, M., \& Xu, C. (2017). A novel change feature-based approach to predict the impact of current proposed engineering change. Advanced Engineering Informatics, 33, 132-143. https://doi.org/10.1016/j.aei.2017.06.002

Do, N. (2018). Identifying experts for engineering changes using product data analytics. Computers in Industry, 95, 81-92. https://doi.org/10.1016/j.compind.2017.12.004

Eide, A. E., Saether, E. A., \& Aspelund, A. (2020). An investigation of leaders' motivation, intellectual leadership, and sustainability strategy in relation to Norwegian manufacturers' performance. Journal of Cleaner Production, 254, 120053. https://doi.org/10.1016/j.jclepro.2020.120053

González-Benito, J., \& González-Benito, O. (2005). A study of the motivations for the environmental transformation of companies. Industrial Marketing Management, 34(5), 462475. https://doi.org/10.1016/j.indmarman.2004.08.005

Grieco, A., Massimo Pacella, M., \& Blaco, M. (2017). On the application of text clustering in engineering change process. In the 10th CIRP Conference on Intelligent Computation in Manufacturing Engineering - CIRP ICME'1, Procedia CIRP, 62, 187-192. https://doi.org/10.1016/j.procir.2016.06.019

Howard, J., Gagné, M., Morin, A. J. S., \& Van den Broeck, A. (2016). Motivation profiles at work: a self-determination theory approach. Journal of Vocational Behavior, 95-96, 74-89. https://doi.org/10.1016/j.jvb.2016.07.004

Huang, G. Q., Yee, W. Y., \& Mak, K. L. (2003). Current practice of engineering change management in Hong Kong manufacturing industries. Journal of Materials Processing Technology, 139(1-3), 481-487. https://doi.org/10.1016/S0924-0136(03)00524-7

Iakymenko, N., Romsdal, A., Semini, M., \& Strandhagen, J. O. (2018). Managing engineering changes in the engineer-toorder environment: challenges and research needs. IFAC $\mathrm{Pa}$ persOnLine, 51(11), 144-151. https://doi.org/10.1016/j.ifacol.2018.08.249

Kuvaas, B., Buch, R., Weibel, A., Dysvik, A., \& Nerstad, C. G. L. (2017). Do intrinsic and extrinsic motivation relate differently to employee outcomes? Journal of Economic Psychology, 61, 244-258. https://doi.org/10.1016/j.joep.2017.05.004

Lau, C. M., Scully, G., \& Lee, A. (2018). The effects of organizational politics on employee motivations to participate in target setting and employee budgetary participation. Journal of Business Research, 90, 247-259.

https://doi.org/10.1016/j.jbusres.2018.05.002

Maslow, A. H. (1943). A theory of human motivation. Psychological Review, 50(4), 370-396.

https://psychclassics.yorku.ca/Maslow/motivation.htm

Mitchell, R., Schuster, L., \& Jin, H. S. (2020). Gamification and the impact of extrinsic motivation on needs satisfaction: making work fun? Journal of Business Research, 106, 323-330. https://doi.org/10.1016/j.jbusres.2018.11.022

Ozkeser, B. (2019). Impact of training on employee motivation in human resources management. In the 3rd World Conference on Technology, Innovation and Entrepreneurship (WOCTINE). Procedia Computer Science, 158, 802-810. https://doi.org/10.1016/j.procs.2019.09.117

Pikosz, P., \& Malmqvist, J. (1998). A comparative study of engineering change management in three Swedish engineering companies. In Proceedings of the DETC98 ASME design engineering technical conference, 78-85.

https://www.researchgate.net/profile/Johan_Malmqvist/ publication/228560763_A_comparative_study_of_engineering_change_management_in_three_Swedish_companies/ links/0046351ed8adf5c284000000/A-comparative-study-ofengineering-change-management-in-three-Swedish-companies.pdf

Rusu, G., \& Avasilcai, S. (2014). Linking human resources motivation to organizational climate. Procedia - Social and Behavioral Sciences, 124, 51-58.

https://doi.org/10.1016/j.sbspro.2014.02.459

Schuh, G., Gartzen, T., Soucy-Bouchard, S., \& Basse, F. (2017). Enabling agility in product development through an adaptive engineering change management. In the 50th CIRP Conference on Manufacturing Systems. Procedia CIRP, 63, 342-347. https://doi.org/10.1016/j.procir.2017.03.106

Schuh, G., Prote, J.-P., Luckert, M., Basse, F., Thomson, V., \& Mazurek, W. (2018). Adaptive design of engineering change management in highly iterative product development. In the 28th CIRP Design Conference, Nantes, France, Procedia CIRP, 70, 72-77. https://doi.org/10.1016/j.procir.2018.02.016

Shaikh, I. A., \& O'Connor. G. O. (2020). Understanding the motivations of technology managers in radical innovation decisions in the mature R\&D firm context: an agency theory perspective. Journal of Engineering and Technology Management, 55, 101553. https://doi.org/10.1016/j.jengtecman.2020.101553

Shakirov, E., Brandl, F. J., Bauer, H., Kattner, N., Becerril, L., Fortin, C., Lindermann, U., Reinhart, G., \& Uzhinsky, I. (2019). Integration of engineering and manufacturing change management: infrastructure and scenarios for teaching and demonstration. In the CIRP Manufacturing Systems Conference, Procedia CIRP, 81, 535-540. https://doi.org/10.1016/j.procir.2019.03.151

Siddharth, L., \& Sarkar, P. (2017). A methodology for predicting the effect of engineering design changes. In the 27th CIRP Design, Procedia CIRP, 60, 452-457. https://doi.org/10.1016/j.procir.2017.03.071

Singh, N., Jain, S., \& Sharma, P. (2015). Motivations for implementing environmental management practices in Indian industries. Ecological Economics, 109, 1-8. https://doi.org/10.1016/j.ecolecon.2014.11.003 
Ullah, I., Tang, D., \& Yin, L. (2016). Engineering product and process design changes: a literature overview. In the 9 th International Conference on Digital Enterprise Technology - DET 2016 - "Intelligent Manufacturing in the Knowledge Economy Era”, Procedia CIRP, 56, 25-33.

https://core.ac.uk/download/pdf/82076272.pdf

VDA. (2010). VDA ECM Recommendation - Part 0 (ECM). SASIG, PRO-STEP IVIP, VDA. https://www.prostep.org/ fileadmin/downloads/VDA_ECM_Recommendation_-_ Part_0_ECM_V2.0.3.pdf

Yu, J., Liu, R., \& Chen, F. (2020). Linking institutional environment with technological change: the rise of China's flat panel display industry. Technological Forecasting \& Social Change, 151, 119852. https://doi.org/10.1016/j.techfore.2019.119852

Zheng, P., Chen, C-H., \& Shang, S. (2019). Towards an automatic engineering change management in smart product service systems - a DSM-based learning approach. Advanced Engineering Informatics, 39, 203-213.

https://doi.org/10.1016/j.aei.2019.01.002 